\title{
The protective effect of celery (Apium graveolens L.) ethanol extract on anemia in 5/6 subtotal nephrectomy rat model
}

\author{
Afifah*, Khusnul Muflikhah**, Tri Lestari***, Eman Sutrisna*, \\ Ajeng Sekar Kirana*, and Sindy Devi Prastiwi*
}

\begin{abstract}
BACKGROUND

Anemia is a frequent complication of chronic kidney disease (CKD). Anemia in CKD is associated with reduced quality of life, increased cardiovascular disease, cognitive impairment, and mortality. Therefore it is necessary to find an alternative agent for preventing anemia in CKD. Celery is one of the natural substances that have anti-inflammatory, antioxidant, and antihypertensive pharmacological effects. Based on the mechanism of CKD and its progression, celery is thought to prevent anemia in CKD. This research was aimed at evaluating the protective effect of celery extract against anemia in a CKD rat model.
\end{abstract}

\section{METHODS}

This was an experimental laboratory study using 25 male Sprague Dawley rats, aged 2-3 months, they were randomized into 5 groups, namely group A, sham operation; group B, subtotal nephrectomy; group C, D, E, subtotal nephrectomy $+250,500,1000 \mathrm{mg} / \mathrm{kg} \mathrm{BW}$ ethanol extract of celery, respectively. The administration of celery extract was performed 14 days before and 14 days after induction of 5/6 subtotal nephrectomy. The hematological parameters ( $\mathrm{Hb}, \mathrm{RBC}, \mathrm{Ht}, \mathrm{MCV}, \mathrm{MCH}, \mathrm{MCHC}$ ) and serum creatinine level were measured at the end of the study. Data were analyzed with One Way ANOVA and Kruskal-Wallis test followed by Mann-Whitney test at $\mathrm{p}<0.05$.

\section{RESULTS}

There were no significant differences between groups in $\mathrm{Hb}, \mathrm{RBC}, \mathrm{Ht}$, $\mathrm{MCV}(\mathrm{p}>0.05)$ and significant differences between groups in $\mathrm{MCH}$ and MCHC $(\mathrm{p}<0.05)$. The highest levels of $\mathrm{Hb}, \mathrm{RBC}$, and Ht were found in group $\mathrm{C}$.

\section{CONCLUSION}

Celery ethanol extract at a dose of $250 \mathrm{mg} / \mathrm{kg} \mathrm{BW} /$ day may prevent anemia in the CKD rat model.

Keywords: 5/6 subtotal nephrectomy, celery, chronic kidney disease, hematological parameter, rats
*Department of Pharmacology,

Faculty of Medicine, Universitas Jenderal Soedirman

** Department of Physiology, Faculty of Medicine, Universitas Jenderal Soedirman

*** Department of Clinical Pathology, Faculty of Medicine, Universitas Jenderal Soedirman

\section{Correspondence:}

Afifah

Department of Pharmacology, Faculty of Medicine,

Universitas Jenderal Soedirman

Jl. Dr. Gumbreg, Mersi,

Purwokerto - Jawa Tengah,

Indonesia 53112

Mobile: +6282242637171

Email: afifah2403@gmail.com

Orchid id: 0000-0002-5703-7061

Date of first submission, December 17, 2018

Date of final revised submission,

January 22,2020

Date of acceptance, January 31, 2020

This open access article is distributed under a Creative Commons AttributionNon Commercial-Share Alike 4.0 International License

Cite this article as: Afifah, Muflikhah K, Lestari T, Sutrisna E, Kirana AS, Prastiwi SD. The protective effect of celery (Apium graveolens $\mathrm{L}$ ) ethanol extract on anemia in $5 / 6$ subtotal nephrectomy rat model. Univ Med 2020;39:12-8. doi: 10.18051/UnivMed. 2020.v39.12-18 


\section{INTRODUCTION}

Anemia is a frequent complication of chronic kidney disease (CKD). ${ }^{(1)}$ Anemia is defined as the condition in which the concentration of hemoglobin $(\mathrm{Hb})$ in the blood is below normal. Anemia is also a decrease in red blood cells (RBC) or lowered ability of RBC to carry oxygen. The prevalence of anemia is twice as high in people with CKD (15.4\%) as in the general population $(7.6 \%)$. The prevalence of anemia increases with stage of CKD from $8.4 \%$ at stage 1 to $53 \%$ at stage 5. ${ }^{(2)}$ Anemia in CKD is associated with reduced quality of life and increased cardiovascular disease, hospitalizations, cognitive impairment, and mortality. ${ }^{(3)}$ The main cause of anemia in CKD is the inadequate production of endogenous erythropoietin. Other contributory factors include deficiency of iron, folate, and vitamin B12, blood loss, and infection or inflammation. Erythropoietin is a hormone that acts on the differentiation and maturation of the red blood cell precursors. ${ }^{(4)}$

Chronic kidney disease is a major public health problem affecting $13.5 \%$ of adult Australians and $11 \%$ of the population in the US. ${ }^{(5)}$ The prevalence of CKD in Indonesia was $89 \%$ of those who underwent hemodialysis in 2015. ${ }^{(6)}$ Treatment of anemia in CKD consist of various therapeutic agents, such as iron, erythropoiesis-stimulating agent, and red cell transfusion. The cost incurred for treatment in CKD patients with anemia is higher than in CKD patients without anemia. ${ }^{(7)}$ Therefore it is necessary to develop an alternative agent for preventing anemia in CKD patients. One strategy that can be done to prevent anemia in CKD is using natural substances. Celery is a natural substance that we can find around us and many people have used it as food. Celery is recognized to have anti-inflammatory, ${ }^{(8)}$ antioxidant, ${ }^{(9,10)}$ and antihypertensive pharmacological effects. ${ }^{(11)}$ The anti-inflammatory effects of celery are related to the presence of flavonoids and saponins in celery. ${ }^{(8)}$ Other ingredients that provide antioxidant effects from celery are iridoids, coumarins, and phenolic acids. ${ }^{(9)}$ Based on the mechanism of CKD and its progression, celery is thought to prevent anemia which is a CKD complication. There is no information about the protective effect of celery ethanol extract to prevent anemia in a CKD rat model.

The 5/6 subtotal nephrectomy is a disease model for CKD and has been a mainstay of studies of progressive renal disease. Induction of $5 / 6$ subtotal nephrectomy in mice for two weeks leads to systemic arterial hypertension and to functional and morphological damage of the remnant kidney, which is considered the main characteristics of chronic kidney disease. ${ }^{(12)}$ Based on the background above, the objective of this study was to evaluate the effect of celery in preventing anemia in $5 / 6$ subtotal nephrectomy.

\section{METHODS}

\section{Research design}

This study was an experimental laboratory study with a post-test only control group design. The study was conducted in the Pharmacology Laboratory, while laboratory measurements of the variables were performed in the Biofit Laboratory, Purwokerto from May until July 2018.

\section{Plant material}

Fresh celery was collected from Pratin, Purbalingga, Central Java and was identified in the Environmental Laboratory, Faculty of Biology, Universitas Jenderal Soedirman.

\section{Preparation of celery extract}

Celery was washed and then dried in a drying oven at a temperature of $45^{\circ} \mathrm{C}$. After drying, the celery was then crushed in a disk mill, with a sieve of 60 mesh. It was then put into the extractor container, with the addition of $70 \%$ ethanol. The mixture was extracted with the UltraTurrax disperser (IKA Werke GmbH, Staufen, Germany) at a speed of $1000 \mathrm{rpm}$, and macerated for 24 hours. Filtration of the mixture was performed with a Büchner funnel attached to a vacuum pump. For evaporation of the filtrate a 
vacuum rotary evaporator was used at a temperature of $45^{\circ} \mathrm{C}$ and rotary speed of $90 \mathrm{rpm}$. The extract was transferred into a porcelain dish and placed in a digital oven at $45^{\circ} \mathrm{C}$. The extract was dried 3 times to a constant weight. The solutions made from the extract were prepared freshly each time and were administered orally once daily for 14 days before and 14 days after $5 / 6$ subtotal nephrectomy to the treatment groups.

\section{Experimental animals}

The sample size was determined based on the Federer formula. A total of 25 healthy male Sprague Dawley rats aged 2-3 months and weighing between 150 and 250 grams were included into the study. The rats were divided by simple randomization into 5 groups of 5 animals each. The animals were acclimatized at room temperature $\left(25-30^{\circ} \mathrm{C}\right)$ for 7 days under a 12 hour light and dark cycle with standard rat feed and water ad libitum.

\section{Induction of experimental chronic kidney disease}

Chronic kidney disease was induced by the $5 / 6$ subtotal nephrectomy technique. The animals underwent either $5 / 6$ subtotal nephrectomy or sham surgery under ketamine anesthesia. Briefly, the left kidney was exposed, and the upper and lower poles were tied with silk, followed by right nephrectomy. The peritoneum and skin were then sutured, and the animals were returned to their cages. ${ }^{(12)}$

\section{Experimental procedure}

The rats were randomized into five groups: group A, sham operation; group B, subtotal nephrectomy; group C, subtotal nephrectomy and $250 \mathrm{mg} / \mathrm{kg}$ BW ethanol extract of celery orally; group D, subtotal nephrectomy and $500 \mathrm{mg} / \mathrm{kg}$ BW ethanol extract of celery orally; group E, subtotal nephrectomy and $1000 \mathrm{mg} / \mathrm{kg} \mathrm{BW}$ ethanol extract of celery orally. The administration of celery extract was performed 14 days before and 14 days after $5 / 6$ subtotal nephrectomy. The blood samples were collected by retro-orbital puncture to measure the hematological parameters $(\mathrm{Hb}$, $\mathrm{RBC}, \mathrm{Ht}, \mathrm{MCV}$. MCH. MCHC) and serum creatinine.

\section{Statistical analysis}

Statistical analysis was performed using oneway ANOVA and Kruskal-Wallis test followed by Mann-Whitney test. Differences were considered to be significant at $\mathrm{p}<0.05$.

\section{Ethical clearance}

The study was conducted after obtaining ethical clearance from the Ethics Committee of the Medical Faculty, Universitas Jenderal Soedirman, Purwokerto, Indonesia, under no. $1664 / \mathrm{KEPK} / \mathrm{IV} / 2018$.

\section{RESULTS}

This study used 5/6 subtotal nephrectomy as a CKD model. The impaired kidney function due to CKD was assessed based on serum creatinine levels. Serum creatinine levels after nephrectomy and administration of celery extract are presented in Table 1. We used a normality test with the Shapiro-Wilk test, and Levene test to know the homogeneity of variances. The serum creatinine levels were normal $(\mathrm{p}=0.121)$ and homogenous $(p=0.482)$. The serum creatinine levels showed significant differences between all groups $(p=0.007)$. The serum creatinine level in group B $(1.46 \pm 0.09 \mathrm{mg} / \mathrm{dL})$ was significantly higher than in group $\mathrm{A}$ $(1.32 \pm 0.06 \mathrm{mg} / \mathrm{dL})$, indicating that $5 / 6$ subtotal nephrectomy increased serum creatinine level. The serum creatinine levels in group C $(1.31 \pm$ $0.06 \mathrm{mg} / \mathrm{dL}), \mathrm{D}(1.38 \pm 0.04 \mathrm{mg} / \mathrm{dl})$, and $\mathrm{E}(1.38$ $\pm 0.05 \mathrm{mg} / \mathrm{dL})$ were lower than in group $B$ and there were significant differences in serum creatinine level between group B and groups $\mathrm{C}$ and $\mathrm{E}$, respectively.

The hematological parameters after administration of celery extract 14 days before and 14 days after induction of CKD are presented in Table 1. The data was subjected to 
Table 1. Distribution of creatinine and hematological parameters by treatment groups

\begin{tabular}{lcccccc}
\hline & $\begin{array}{c}\text { Group A } \\
(\mathbf{n = 5})\end{array}$ & $\begin{array}{c}\text { Group B } \\
(\mathbf{n = 5})\end{array}$ & $\begin{array}{c}\text { Group C } \\
(\mathbf{n = 5})\end{array}$ & $\begin{array}{c}\text { Group D } \\
(\mathbf{n = 5})\end{array}$ & $\begin{array}{c}\text { Group E } \\
(\mathbf{n = 5})\end{array}$ & p-value \\
\hline Creatinine $^{\mathrm{a}}$ & $1.32 \pm 0.06^{*}$ & $1.46 \pm 0.09$ & $1.31 \pm 0.06^{*}$ & $1.38 \pm 0.04$ & $1.38 \pm 0.05^{*}$ & 0.007 \\
$\mathrm{Hb} \mathrm{(g/dL)})^{\mathrm{a}}$ & $10.82 \pm 1.9$ & $10.04 \pm 0.6$ & $10.20 \pm 0.8$ & $10.12 \pm 1.6$ & $9.94 \pm 0.9$ & 0.823 \\
$\mathrm{RBC}\left(\mathrm{x} 10^{6} / \mu \mathrm{l}\right)^{\mathrm{a}}$ & $5.75 \pm 1.9$ & $4.18 \pm 1.0$ & $6.40 \pm 1.0$ & $4.49 \pm 1.4$ & $4.48 \pm 0.4$ & 0.067 \\
$\mathrm{Ht}(\%)^{\mathrm{a}}$ & $33.1 \pm 11.1$ & $25.72 \pm 5.8$ & $36.62 \pm 5.5$ & $25.90 \pm 8.0$ & $25.42 \pm 2.1$ & 0.079 \\
$\mathrm{MCV}(\mathrm{fl})^{\mathrm{b}}$ & 60.20 & 60.80 & 58.30 & 57.60 & 58.10 & 0.386 \\
$\mathrm{MCH}(\mathrm{pg})^{\mathrm{b}}$ & 17.20 & $20.10^{\#}$ & 15.20 & $20.40^{\#}$ & $22.80^{\#}$ & 0.024 \\
$\mathrm{MCHC}(\mathrm{g} / \mathrm{dL})^{\mathrm{b}}$ & 28.50 & $33.10^{\#}$ & 26.00 & $36.30^{\#}$ & $40.30^{\#}$ & 0.025 \\
\hline
\end{tabular}

Data presented as mean $\pm \mathrm{SD}$, except for $\mathrm{MCV}, \mathrm{MCH}$ and $\mathrm{MCHC}$ as median

${ }^{a}$ One-way ANOVA and post-hoc independent $-\mathrm{t}$ test. ${ }^{b}$ Kruskal-Wallis and Post Hoc Mann-Whitney test. ${ }^{*}=\mathrm{p}<0.05$ vs group $\mathrm{B} ;{ }^{\#}=\mathrm{p}<.0 .05$ vs group C. Group A/sham operation: group with sham operation + distilled water; group B/nephrectomy: CKD model + distilled water; group C: CKD model+ethanol extract of celery $250 \mathrm{mg} / \mathrm{kg} \mathrm{BW}$; group D: CKD model+ethanol extract of celery $500 \mathrm{mg} / \mathrm{kg} \mathrm{BW}$; group E: CKD model+ethanol extract of celery $1000 \mathrm{mg} / \mathrm{kg} \mathrm{BW}$.

normality test with the Shapiro-Wilk test and the Levene test to know the homogeneity of variances. The results of the normality test were normal for $\mathrm{Hb}, \mathrm{RBC}$, and $\mathrm{Ht}$, but not for $\mathrm{MCV}$, $\mathrm{MCH}$ and MCHC.

Furthermore, a one-way ANOVA statistical test was performed on $\mathrm{Hb}, \mathrm{RBC}$, and $\mathrm{Ht}$, and Kruskal-Wallis test on $\mathrm{MCV}, \mathrm{MCH}$, and $\mathrm{MCHC}$. The results of the one-way ANOVA test showed that there were no significant differences in mean $\mathrm{Hb}, \mathrm{RBC}$, and Ht levels ( $\mathrm{p}>0.05$ ). The KruskalWallis test showed that $\mathrm{MCH}$ and $\mathrm{MCH}$ were significantly different between all groups $(\mathrm{p}=0.024$ and $\mathrm{p}=0.025$, respectively). The Mann-Whitney test on $\mathrm{MCH}$ and $\mathrm{MCHC}$ showed significant differences between group $\mathrm{C}$ and groups $\mathrm{B}, \mathrm{D}$, and $\mathrm{E}$, respectively.

\section{DISCUSSION}

Serum creatinine level is one parameter that has been used to represent kicney function. This study showed that serum creatinine level in the 5/6 subtotal nephrectomy group was significantly higher than that in the sham operation group. This result showed that the induction of 5/6 subtotal nephrectomy increased the serum creatinine level, indicating a decline in renal function. According to Gava et al., ${ }^{(12)}$ and Layal et al., ${ }^{(13)}$ 5/6 subtotal nephrectomy increases the level of serum creatinine, showing the presence of renal disturbances. The serum creatinine levels in groups $\mathrm{C}, \mathrm{D}$, and $\mathrm{E}$ were lower than in group B, and group C had the lowest serum creatinine level, signifying that the administration of ethanol extract of celery decreased the serum creatinine level.

Another function of the kidneys is producing erythropoietin (EPO), a molecule that stimulates the formation of RBC. Disorders in the kidneys disrupt the formation of RBC, causing anemia, which is an almost irreducible complication of CKD. Anemia occurs more frequently in patients with advanced kidney dysfunction and relates to the quality of life and mortality in CKD patients. ${ }^{(14)}$ Anemia in CKD is mainly due to the inadequate amount of EPO production of injured kidneys, and the EPO deficiency is proposed to be the central feature of CKD associated anemia. ${ }^{(3)}$

The means of $\mathrm{Hb}, \mathrm{RBC}$, and $\mathrm{Ht}$ in this study showed no significant differences between all groups, but it can be seen that the means of $\mathrm{Hb}$, $\mathrm{RBC}$, and $\mathrm{Ht}$ were lower in group B compared to group $\mathrm{A}$. This shows that CKD induction using 5/6 subtotal nephrectomy decreased the level of $\mathrm{Hb}, \mathrm{RBC}$, and $\mathrm{Ht}$. Corresponding to the research of Cahyawati et al., ${ }^{(15)} 5 / 6$ subtotal nephrectomy decreases the hematological parameters at 2 weeks after induction. According to Sun et al., ${ }^{(16)}$ in a CKD mouse model with adenine induction, erythropoietin levels began to decline in the first week of CKD induction, but the hemoglobin level decreased significantly in the fourth week, even though kidney damage already looked significant in the second week. 
The mean $\mathrm{Hb}$ and $\mathrm{RBC}$ levels of group $\mathrm{C}$, $\mathrm{D}$, and $\mathrm{E}$ (CKD rat model given ethanol extract of celery) tended to be higher than in group $\mathrm{B}$ (CKD rat model without ethanol extract of celery), showing the function of active substances in celery in preventing a decrease in $\mathrm{Hb}$ and $\mathrm{RBC}$ levels. Celery contains active ingredients that have antioxidant and anti-inflammatory properties such as saponins, flavonoids (quercetin, tannins), polyphenols, iridoids, phenolic acids, and coumarins which can prevent the progression of CKD by inhibiting the occurrence of inflammation and oxidative stress. ${ }^{(17)}$

As an antioxidant, flavonoids prevent cellular component damage due to chemical reactions involving free radicals. Some mechanisms are to deactivate ROS and stimulate the production of antioxidants. ${ }^{(18)}$ Antioxidant properties are also shown by phenolic acids which have the effect of preventing the formation of ROS. ${ }^{(19)}$ Anemia of CKD has also been reported to be associated with the suppressive effects of pro-inflammatory cytokines on erythropoiesis, which cause the anemia of inflammation. ${ }^{(20)}$ Anti-inflammatory effects of celery arise through several mechanisms. Flavonoids and saponins have antiinflammatory effects by inhibiting the formation of cyclooxygenase 2 (COX-2), while iridoids act by inhibiting pro-inflammatory NF- $\mathrm{KB}$ p 65 gene expression. ${ }^{(21,22)}$ Coumarin inhibits the formation of superoxide anions and can inhibit the production of COX. By inhibiting the progression of CKD by celery active substances, the decline in kidney function that causes CKD complications such as anemia can be prevented. ${ }^{(23-26)}$ Besides flavonoids, especially quercetin types can inhibit 2,2-azo-bis (2-amidinopropane) dihydrochloride (AAPH) (free radicals that cause oxidative damage to erythrocyte membranes causing erythrocyte hemolysis). Prevention of hemolysis of erythrocytes can prevent a decrease in the number of erythrocytes and hemoglobin levels in the blood. ${ }^{(19)}$ Although the difference in mean hemoglobin levels between groups $\mathrm{C}, \mathrm{D}$, and $\mathrm{E}$ was not significant, among the 3 groups it was found that group $\mathrm{C}$, receiving celery ethanol extract at a dose of $250 \mathrm{mg} / \mathrm{kg} \mathrm{BW} /$ day orally, had the highest mean $\mathrm{Hb}, \mathrm{RBC}$ and Ht levels. The results in the $\mathrm{D}$ and $\mathrm{E}$ groups are influenced by the dose factor. The serum creatinine level at the dose of $250 \mathrm{mg} / \mathrm{kg} \mathrm{BW} /$ day of celery extract, was the lowest compared to the doses of 500 $\mathrm{mg} / \mathrm{kg} \mathrm{BW} /$ day and $1000 \mathrm{mg} / \mathrm{kg} \mathrm{BW} /$ day. In patients with kidney disease such as CKD, celery should not be given at too high doses because it can have adverse effects. ${ }^{(27)}$ At low doses, flavonoids have antioxidant effects, but at high doses, the flavonoids in celery can produce prooxidative effects by stimulating the formation of reactive oxygen species (ROS). ${ }^{(19)}$

The mean $\mathrm{MCH}$ and $\mathrm{MCHC}$ in this study were significantly different between groups $\mathrm{C}$ and B. The $\mathrm{MCV}, \mathrm{MCH}$, and $\mathrm{MCHC}$ values were characteristic for the type of anemia, which in CKD is typically normocytic, normochromic and hypoproliferative. It is most commonly caused by decreased erythropoietin production and/or iron deficiency. ${ }^{(3)} \mathrm{A}$ similar study needs to be carried out to assess the erythropoietin and iron levels with a duration of at least 4 weeks after CKD induction. ${ }^{(15)}$

One limitation of this study was the relatively short time from operation until termination in which to obtain samples. Therefore, anemia, the complication of CKD, was not yet apparent. The implication of this study is that it can be applied to CKD high risk populations, such as patients using nephrotoxic drugs, patients with diabetes mellitus, and patients with hypertension, to prevent $\mathrm{CKD}$ and its complication.

\section{CONCLUSIONS}

Celery ethanol extract at a dose of $250 \mathrm{mg} /$ kg BW may prevent anemia in the $5 / 6$ subtotal nephrectomy rat model.

\section{CONFLICT OF INTEREST}

The authors declared no conflict of interests. 


\section{ACKNOWLEDGEMENT}

This study was supported by research grants (BLU) from Unsoed.

\section{CONTRIBUTORS}

$\mathrm{AA}, \mathrm{KM}, \mathrm{TL}$, and ES contributed to the basic concept and design of the study. AA, KM contributed to writing the manuscript and performing the experiment. AA, KM, ASK, SDP contributed to sample preparation and data collection. AA contributed to the statistical analysis. All authors have read and approved the final manuscript.

\section{REFERENCES}

1. Cases A, Egocheaga M, Salvador T, et al. Anemia of chronic kidney disease: protocol of study, management and referral to nephrology. Nefrologia 2018;38:8-12. doi: 10.1016/j.nefroe. 2018.01.007.

2. Staufer M, Fan T. Prevalence of chronic kidney disease in the United States. PLoS One 2014;9:e84943. doi:10.1371/journal.pone.0084943.

3. Babitt JL, Lin HY. Mechanisms of anemia in CKD. J Am Soc Nephrol 2012;23:1631-4. doi: 10.1681/ ASN.2011111078.

4. Padhi S, Glen J, Pordes BAJ, Thomas ME for the Guideline Development Group. Management of anaemia in chronic kidney disease: summary of updated NICE guidance. BMJ 2015;350:h2258. doi: 10.1136/bmj.h2258.

5. Fassett RG, Venuthurupalli SK, Gobe GC, Coombes JS, Cooper MA, Hoy WE. Biomarkers in chronic kidney disease: a review. Kidney Int 2011;80:80621. doi: 10.1038/ki.2011.198.

6. Perkumpulan Nefrologi Indonesia (PERNEFRI). 8th Report of Indonesian Renal Registry. Jakarta; 2015.

7. Azalea M, Andayani TM, Satibi. Analisis biaya pengobatan penyakit ginjal kronik rawat inap dengan hemodialisa di rumah sakit. J Manaj Pelayanan Farm 2016;6:141-50. doi: 10.22146/ jmpf.266.

8. Taylor P, Baananou S, Borgi W, Mahmoud A, Boukef K, Chouchane N. Anti-inflammatory and analgesic activities of Tunisian Apium graveolens $\mathrm{L}$. leaves extracts in rats. J Biol Act Prod Nat 2013;4:37-41. doi: 10.1080/22311866. 2012.10719129.
9. Sameh B, Ibtissem B, Mahmoud A, Boukef K, Naceur A. Antioxidant activity of Apium graveolens extracts. J Biol Act Prod Nat 2011;1: 340-3. doi: 10.1080/22311866.2011.10719102.

10. Kooti W, Daraei N. A review of the antioxidant activity of celery (Apium graveolens L). J Evid Based ComplemAltern Med 2017;22:1029-34. doi: 10.1177/2156587217717415.

11. Kooti W, Ali-Akbari S, Asadi-Samani M, Ghadery H, Ashtary-Larky D. A review on medicinal plant of Apium graveolens. Adv Herb Med 2014;1:4859.

12. Gava AL, Freitas FPS, Balarini CM, Vasquez EC, Meyrelles SS. Effects of 5/6 nephrectomy on renal function and blood pressure in mice. Int J Physiol Pathophysiol Pharmacol 2012;4:167-73.

13. Layal K, Perdhana IS, Louisa M, Estuningtyas A, Soetikno V. The effects of quercetin on oxidative stress and fibrosis markers in chronic kidney disease rat model. Med J Indones 2017;26:16977. doi: $10.13181 / \mathrm{mji}$.v26i3.1462.

14. Voormolen N, Grootendorst DC, Urlings TAJ, et al. Prevalence of anemia and its impact on mortality and hospitalization rate in predialysis patients. Nephron Clin Pract 2010;115:c113-c141. doi: 10.1159/000312876.

15. Cahyawati PN, Aryastuti AASA, Ariawan MBT, Arfian N, Ngatidjan N. Statin and anemia in chronic kidney disease (CKD): an experimental study. In: Abdullah AG, Nandiyanto BD, editors. Pharmacology. AASEC 2018: Proceedings of the 3th Annual Applied Science and Engineering Conference; 2018 April 18; Bandung, Indonesia: EDP Sicences;2018.p.1-4. doi: 10.1051/matecconf 1201819707003.

16. Sun CC, Vaja V, Chen S, et al. A hepcidin lowering agent mobilizes iron for incorporation into red blood cells in an adenine-induced kidney disease model of anemia in rats. Nephrol Dial Transplant 2013;28:1733-43. doi: 10.1093/ndt/gfs584.

17. Dewi KEM, Walanda KD, Sabang SM. Effect of celery (Apium graveolens L.) extract against the solubility of calcium kidney stones. J Akad Kim 2016;5:127-32.

18. Prochazkova D, Bousova I, Wilhelmova N. Antioxidant and prooxidant properties of flavonoids. Fitoterapia 2011;82:513-23. doi: 10.1016/j.fitote.2011.01.018.

19. Beloborodova N, Bairamov I, Olenin A, Shubina V, Teplova V, Fedotcheva N. Effect of phenolic acids of microbial origin on production of reactive oxygen species in mitochondria and neutrophils. J Biomed Sci 2012;19:89. doi: 10.1186/1423-012719-89. 
20. Fraenkel PG. Anemia of inflammation: a review. Med Clin NorthAm 2017;101:285-96. doi: 10.1016/ j.mcna.2016.09.005.

21. Lee Y, Jung J-C, Ali Z, Khan IA, Oh S. Antiinflammatory effect of triterpene saponins isolated from blue cohosh (Caulophyllum thalictroides). Evid Based Complem Altern Med 2012;2012:1-8. doi: 10.1155/2012/798192.

22. Liu X, Wang J. Anti-inflammatory effects of iridoid glycosides fraction of Folium syringae leaves on TNBS-induced colitis in rats. J Ethnopharmacol 2011;133:780-7. doi: 10.1016/ j.jep.2010.11.010.

23 Kirsch G, Abdelwahab AB, Chaimbault P. Natural and synthetic coumarins with effects on inflammation. Molecules 2016;21:1322:1-13. doi: 10.3390/molecules21101322.
24 Venugopala KN, Rashmi V, Odhav B. 2013. Review on natural coumarin lead compounds for their pharmacological activity. BioMed Research International 2013;2013:963248. doi: 10.1155/2013/ 963248

25. Kazanciodlu R. Risk factors for chronic kidney disease: an update. Kidney Int Suppl 2013;3:368 71. doi: 10.1038/kisup.2013.79.

26. Walt I, Swanepoel CR, Mahala B, Meyers AM. Important complications of chronic kidney disease. S Afr Med J 2015;105:4. doi: 10.7196/ SAMJ.9536.

27. Yaser AJ, Muneer A, Abdelhafid B, Fawzia A. Chemical composition, phytochemical constituents and antioxidant activities of the seeds extract of Apium graveoleus L from Yemen. Res J Pharm Biol Chem Sci 2014;5:1074-87. doi: 0.7897/2230-8407.04915. 